December 31st she was allowed to have a little barley water. She vomited, at 11 P.M. on that day, a little greenish fluid; and on January 1st was ordered to have milk and soda, barley water, and koumiss. The general condition good. The abdomen was a little distended; flatus was passing freely. She was given a turpentine enema on this night. No fæces passed, but some flatus and the remains of the nutrient enemata. After this the patient went on steadily towards recovery. There was no further vomiting. On January 9th she had a sponge bun. On January 19th some fish, and on January 21st some fowl. On January 25th she got up, and on February 9 th went for a drive.

From time to time I have seen Mrs. R. since she passed from my direct observation. In the course of a few months she resumed her ordinary duties, and gradually she found herself able to enjoy unconscious digestion. At the present time she is in very good health, and shows no sign of having suffered from any serious disease.

\section{Examination of Tumour}

Length $1 \frac{1}{2}$ inch ; circumference 6 inches. The pyloric opening barely admitted the tip of the little finger; the stomach wall was much thickened, the duodenal wall less so. At the lower part of the pyloric opening was a saucer-shaped ulcer of the size of a shilling, with thickened base and edges.

Microscopically. - The chief bulk of the tumour consists of densely packed fibrous tissue, with intervening small round cells. Here and there in the interstices of the fibrous tissue are the remains of degenerated glands. In the deeper layers of the section, outside the fibrous tissue these glands are numerous.

\section{FECAL FISTULA OF TWO YEARS AND TWO MONTHS' STANDING FOLLOWING HERNIOTOMY FOR STRANGULATED HERNIA : OPERATION : CURE.}

By ANTHONY BOWLBY, F.R.C.S., Assistant Surgeon to St. Bartholomew's Hospital.

THE following case presents several interesting features. In the first place it is very rare to find the intestine give way as long as a month after herniotomy. I have myself seen it perforate as late as the ninth day, but not later. It is evident that the precaution of leaving the damaged gut near to the femoral ring allowed it to contract adhesions in a position which was a favourable one for the escape of its contents, and it is fairly certain that had it been placed in the mids of the peritoneal cavity acute peritonitis would have ensued.

E. D., aged 66, was admitted into St. Bartholomew's Hospital on March 3rd, 1893, suffering from a fæcal fistula in the right groin of two years and two months' standing.

His history was that in January, 1890, he was admitted into St. Mary's Hospital suffering from a strangulated right femoral hernia, and that after operation he made a good recovery, and left the hospital with the wound closed at the end of three weeks. The registrar's note at St. Mary's Hospital recorded the following observation: "Gut deeply congested; sulci where nipped; returned into abdomen; sac removed but not ligatured; drainage tube passed into abdomen and removed next day."

A week after leaving hospital an abscess formed at the site of the operation and discharged spontaneously. The discharge of the pus was followed by escape of fæcal matter, and this steadily increased in quantity. At the end of a year, however, the wound closed for three weeks, and then again reopened. For the next year he gradually passed more and more fæcal matter by the wound, and for the last three months before admission had passed nothing by the rectum, except when an aperient was taken, the whole of the fæces passing for several weeks at a time by the fistulous opening. He also began to lose flesh quickly, and had gone down 2 stone in weight. It was under these circumstances that Dr. E. J. Lewis advised him to submit to an operation for relief.

Condition on Admisszon.-Fairly well nourished. In the right groin is a sinus in the situation of the crural canal. It admits with difficulty the tip of the little finger, but soon narrows so as only to allow the passage of a director. The sinus constantly discharges liquid fæces and the skin around is excoriated and sore. On the left side is a scrotal hernia with an undescended testis. The viscera are generally healthy.

He was kept in bed and fed on light diet, and it was. observed that his statement as to the absence of evacuation by the rectum was true, the bowels being only opened per rectum by aperients. A few hard, scybalous masses could sometimes be removed by enemata. Charcoal taken by the mouth was observed at the fistula forty-eight hours later. After consultation, it was decided to operate at the seat of the fistula.

On March 20th a vertical incision was made, opening up the fistula and dividing in part Poupart's ligament. It was found that a piece of small intestine occupied the crural ring and was drawn by the scar tissue a little way into the canar. It was dissected from the surrounding parts with some difficulty, owing to the very narrow space available, and was then discovered to have an opening in it half an inch in length. Into this aperture the opposing mucous membrane bulged. This opening was closed by a series of Lembert's sutures of fine silk, and the gut was placed in the abdomen just clear of the crural ring. It did not appear that the general peritoneal cavity was exposed during the operation, the neighbouring coils of intestine being adherent. The skin incision was not closed. Two days later fæces again passed by the wound, and continued to do so in considerable quantities for the next week. After that time the discharge rapidly lessened, so that by April 18th it was noticed that only about half a teaspoonful of discharge escaped in twentyfour hours. The bowels also acted regularly, with the assistance of a slight laxative, and sometimes for a day or two no flatus passed by the fistulous opening.

For the next month progress was not so satisfactory; the parts around the wound were a good deal inflamed, and he also suffered from an attack of inflammation of the right testis. The quantity of fæcal discharge varied much, but on the whole it diminished.

By June 3rd the discharge was simply purulent, and contained no fæces. On this day he was put under an anæsthetic, and as the escape of pus did not seem quite free, the aperture in the skin was enlarged, and the mouth of the sinus erased. A little rough exposed bone was discovered near the pubic crest. From this time improvement was rapid. For a week at a time no fæces escaped, and after June 20 th he never passed flatus by the wound.

On July 21 st he was discharged, the sinus still being open, but no fæcal matter escaping.

On October 30th the patient came to show himself. $\mathrm{He}$ said that the sinus had healed finally a week or two after leaving the hospital, and an examination of the parts showed a sound, firm cicatrix. The man had gained a stone and a half in weight, and his bowels were open naturally. He had returned to his work as a bootmaker. A year later-that is, in November, 1894, he remained in good health and with a sound scar.

The result of the small plastic operation performed was most satisfactory. At first I was disposed to treat the artificial anus by resection of intestine and suture; but, considering the very considerable risks of such a proceeding in an old man. I came to the conclusion that it was better to see what could be done by less severe measures. I have chiefly brought the case forward as one which encourages the performance of such a comparatively trivial operation, for there is a tendency at present to consider that long-standing fæcal fistula after hernia requires resection of intestine for its cure: and seeing that in my patient the fistula was of more than two years' standing, it is evident that mere duration does not call for the performance of the more serious of the two operations which may be employed.

AT a meeting of the Berlin Medical Society on January 9th Professor Virchow was re-elected President for the ensuing year.

JoHn McPhair Dodgall, M.D., M.B., C.M., was unanimously elected Chairman (from outside) of the Parish Council of the parish of Welburn, near York. 